\title{
丛枝-泡貫菌根真菌一中国球軎震在 离体条件下的生长和产狍
}

\author{
彭生诚沈崇尧
}

(北京农业大学植保系)

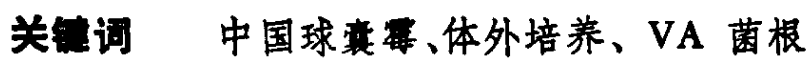

丛枝-泡暻菌根（Vesicular-arbuscular mycorrhizae，VAM）真菌在离开寄主组织条件下 的纯培养一直没有得到很好的解决, 致使这类真菌的分类、遗传和生理研究以及它们在生产上 的应用都有很大的局限性. 由于 VAM 真菌在生产上应用的潜能, 关于它们的纯培养及接种 体生产的研究受到了极大的重视,本文以中国球景霉 (Glomus sinensis Peng \& Shen) 为材 料, 研究了它在低温 $\left(0-4^{\circ} \mathrm{C}\right)$ 和液体培养等特殊条件下的孢子发芽、菌丝生长和“无性孢子”的 发生,讨论了这类真菌在离开寄主组织条件下纯培养的可能性.

\section{一、材料和方法}

1. 真及其策硫 Glomus sinensis Peng \& Shen 由作者在北京市郊蔬菜地中采用湿 篮法 ${ }^{[1]}$ 分离. 分离到的真菌用单孢接种法 ${ }^{[2]}$ 扩大培养. 寄主植物根据季节不同而异, 春季 用红三叶草 (Trifolium pratense)，夏季用苏丹草 (Sorghum sudanense)，冬季用小麦 (Triticum aestivum)。培养基质为砂: 土(3:1)的混合物, 接种前在 $121^{\circ} \mathrm{C}$ 下灭菌 $2 \mathrm{~h}$ ，接种 后的植物放在温室中培养, 并每隔 10-20天浇一次无磷的 Hoagland 营养液. 培养时间为 4 个月以上, 然后再用湿篮法分离.

2. 真兽狍子的表面消根据 $\mathrm{Mosse}^{[3]}$ 和 $\mathrm{Koske}^{[4]}$ 的方法改进. 用含 $2 \%$ 的氯铵 T 和 $200 \mathrm{ppm}$ 链素的消毒液在含掂纸夹的布氏漏斗中消毒 $15-20 \mathrm{~min}$, 经表面消毒的孢子咜 于 $0-4^{\circ} \mathrm{C}$ 冰箱中备用.

3. 东菌的狍子发芽、菌丝生长及“无性狍子”的产狍试验作者在实验中偶然发现, 没经 表面消毒的孢子, 放在自来水中, 贮于 $0-4^{\circ} \mathrm{C}$ 的冰箱中保存时, 孢子能稳定地发芽、长出菌丝 并产生“无性孢子”。因此，作者用经表面消毒和没经表面消毒的两类孢子试验了它们在自来 水、蒸馏水和无菌水中, 两种温度条件下 $\left(0-4^{\circ} \mathrm{C}, 20 \pm 1^{\circ} \mathrm{C}\right)$ 的生长情况. 试验在 $90 \mathrm{~mm}$ 的培养 皿中进行, 每皿加约 $20 \mathrm{ml}$ 水, 接人 50 个左右的新鲜孢子, 定期检验狍子发芽及生长情况. 菌丝 长度根据在低倍镜下菌丝与接目尺的交叉格数分成 0-4 级。0 级：不产生明显可见的芽管; 1级: 小于 30 格; 2 级: $30-60$ 格; 3 级: $61-90$ 格;4级: 大于 90 格. 每格长 $26.6 \mu \mathrm{m}$.

4. 玸子害度对发芽的影响该试验用未经表面消毒的孢子, 在自来水中, $0-4^{\circ} \mathrm{C}$ 条件 下进行. 每个处理设 3 个重复. 孢子发芽率根据培养 40 天后的结果计算。

本文1988 年11月9日收到. 1989 年3 月22 日收到修改稍. 


\section{二、结果与讨论}

1. 工贯的狍子发芽、䓪丝生长及“无性狍子”的产生 表 1 列出了在给定的条件下,培养 40 天后的结果. 可以看出, 在自来水中, $0-4{ }^{\circ} \mathrm{C}$ 下, 没经表面消毒的狍子发芽率高, 菌丝伸展 的也长,并稳定地产生“无性孢子”. 在 $20^{\circ} \mathrm{C}$ 时,自来水中也偶尔有少量的孢子发芽,但芽管的 伸长很有限, 并且不产生“无性孢子”. 用蒸馏水和无菌水试验时, 在两种温度下, 孢子均不能 正常发芽. 孢子经表面消毒后也不能正常发芽.

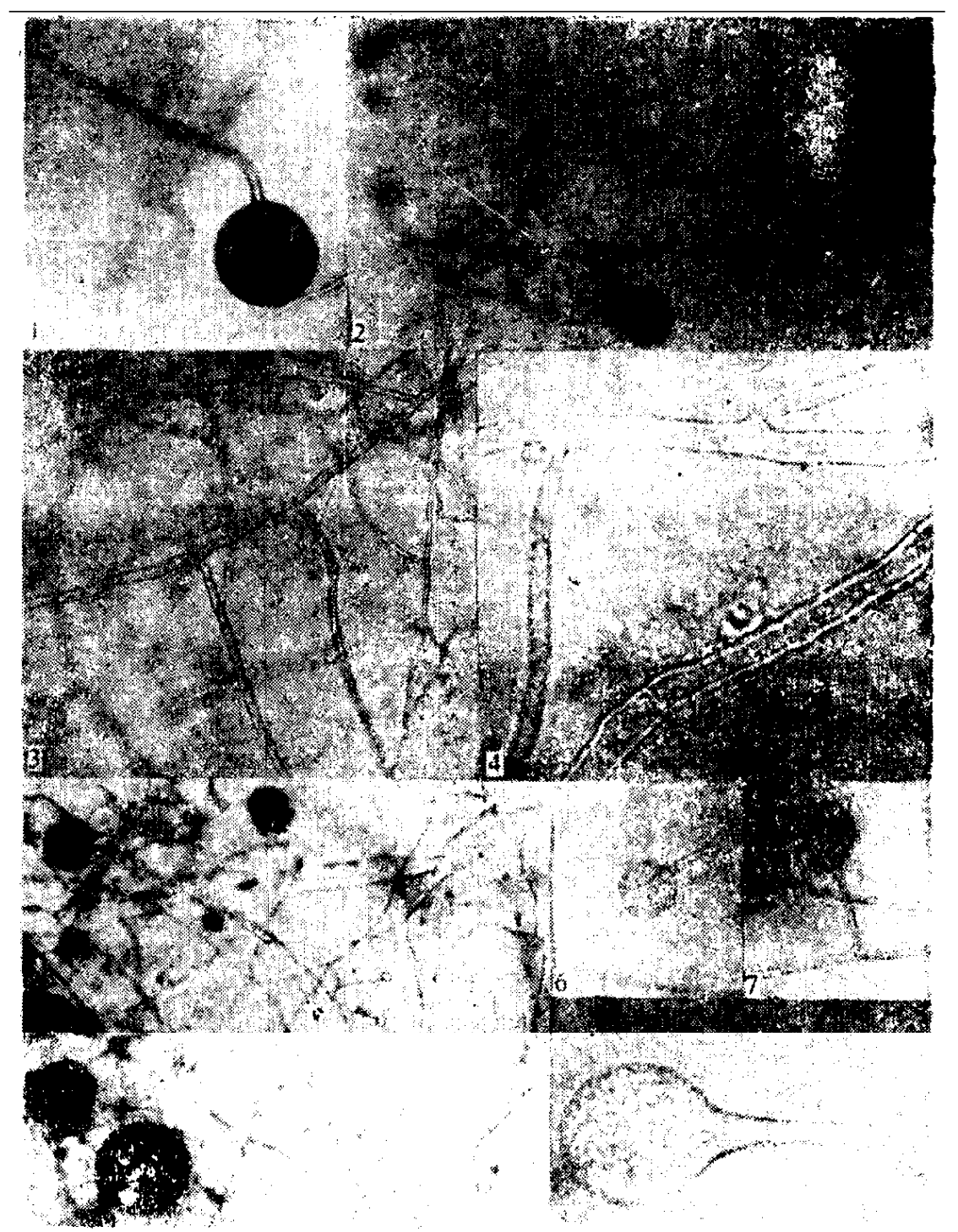

图 1 Glomus sinensis Peng \& Shen 在离体条件下的犯于发芽、棞丝生长和 “无性狍子”产生的过程

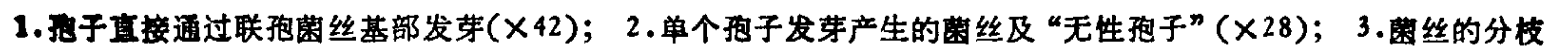

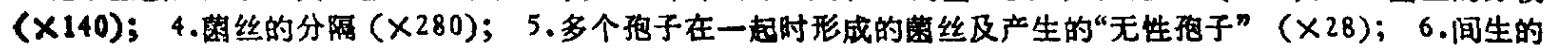
“无性抱子” (X70)； 7.顶生的“无性抱子”(X70)；8.无隔的“无性抱子”( X 280)

没经表面消毒的狍子在 $0-4{ }^{\circ} \mathrm{C}$ 条件下,在自来水中培养时,开始几天芽管的产生很慢,一 般约 10 天后可观察到从联孢菌丝产生芽管(图 1-1), 以后芽管的伸长速度加快, 不久开始产 生分枝,一般在培兼约20天后开始产生少量的“无性孢子”,约 30 天后产孢增加, 这种菌丝的生 长和产孢可延续到 60-80 天. 菌丝生长时, 主要是沿芽管延长, 之后也产生几个分枝（图 1- 
表 1 Glomus sinensis Peng \& Shen 在离体条件下的生长和产指

\begin{tabular}{|c|c|c|c|c|c|}
\hline 培帮基质 & $\begin{array}{l}\text { 温度 } \\
\left({ }^{\circ} \mathrm{C}\right)\end{array}$ & 抱子处理 & $\begin{array}{c}\text { 抱于发芽率 } \\
(\%)\end{array}$ & 菌丝长度* & “営莎拖子”产生 \\
\hline 自来水 & 20 & 表面不消軎 & $6.0 \pm 0.73$ & 1.9 & - \\
\hline 羔塯水 & 20 & 表面不消繁 & - & - & - \\
\hline 无圈水 & 20 & 表面不消每 & - & - & - \\
\hline 自来水 & $0-4$ & 表面不消繁 & $75.3 \pm 3.31$ & 大于 4 & + \\
\hline 㟟㙁水 & $0-4$ & 表面不消䇘 & - & - & - \\
\hline 无畨水 & $0-4$ & 表面不消击 & - & - & - \\
\hline 自来水 & 20 & 表面消数 & - & - & - \\
\hline 自来水 & $0-4$ & 表面消每 & - & - & - \\
\hline
\end{tabular}

*根据棞丝与接目测微尺的交叉格数分级.

一表示不发芽、不产陁; +十表示产孢。

2-3)，菌丝常在分枝处、偶尔也在其它部分产生隔膜（图 1-4）. 菌丝常可伸长到 $1-3 \mathrm{~cm}$, 甚 至更长。“无性孢子”为薄壁透明的小孢子,常着生在菌丝的顶端(图 1-7), 偶尔也着生在菌丝 的中间(图 1-6)，着生“无性狍子”的菌丝均为分枝菌丝,菌丝与“无性狍子”之间无隔(图 1-8)

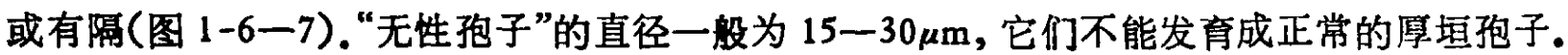

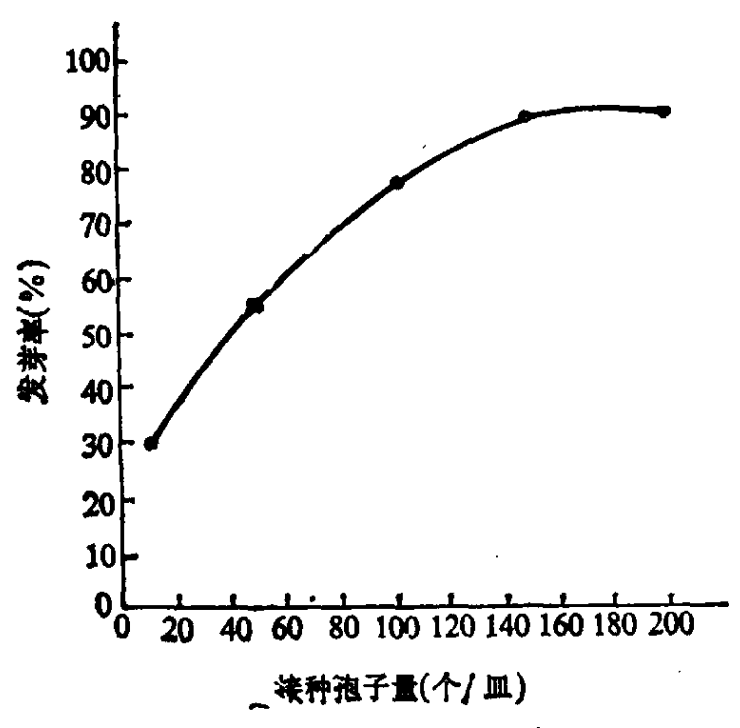

图 2 孢子密度对孢子发芽的影响
2. 狍子密度对发芽的影响

图 2 为㘧 子密度与孢子发芽率的曲线图. 由此可知, 在一定的范围内，孢子发芽率随孢子密度的 增加而增加.

中国球管霉在自来水中, $0-4^{\circ} \mathrm{C}$ 下能稳 定地发牙、生长并能产生“无性孢子”，这是 几种因子综合作用的结果。根据表 1 的数据, 我们可以作出如下推论:（1) 低温 $\left(0-4^{\circ} \mathrm{C}\right)$ 有利于真菌孢子的发芽和产狍.（2）自来水 能促进真菌的生长，并且这中间至少包括了 厌气、水中营养和水中微生物等因子的作用。 作者曾试验将这类真菌放在 $1 \%$ 的琼脂上, 用自来水作营养,在 $0-4^{\circ} \mathrm{C}$ 下培养，但真菌 几乎不能台长(结果没列出)，这就说明了厌气的重要性. 另外,从表 1 可知,蒸馏水和无菌水 都不能象自来水那样刺激真菌生长，这表明水中的营养和水中微生物有利于真菌孢子的发芽 和产孢.（3）真菌孢子的表面因子能刺激孢子的发牙和产狍，因为在本实验条件下孢子一旦 经表面消毒,它的生长能力就完全消失。本文得到的这些结果与前人的某些研究有相似之处.

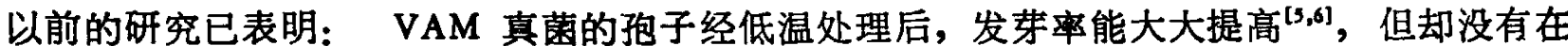
0一 $4^{\circ} \mathrm{C}$ 下就能发芽和产孢的报道. 关于狍子发芽与水分的关系，Daniels 等 ${ }^{[7]}$ 证明，地上生 球震 (Glomus epigaeum) 在湿度高时发芽最好. Koske ${ }^{(4)}$ 也报道，在培养基的水势为 0 bar 时, 珠状巨孢内英電（Gigaspora margarita)的孢子发车率最高,菌丝伸展得也最长. 此 外, 也有人研究表明: 细菌 ${ }^{[9]}$ 、某些土壤微生物 ${ }^{[8]}$ 及 VAM 真菌表面的微生物 ${ }^{\left[{ }^{[9]}\right.}$ 也能促进孢子 的发芽和产孢. 中国球霍霰末经消毒的孢子在水中低温下发芽、生长的结果表明, VAM 真菌 
仼发芽更其后的生长中对營养的要求并不复杂, 仅自来水中的营养就能在一定程度上满足它 的需梹。因此作者认为, 某些其它因子, 如低温处理、厌气、真菌周围的微生物区系等, 对这类 真菌的生长有较重要的影响. 所以, 在研究 VAM 真菌的体外培养时, 除了从营齐的角度去 饰选培养基外，同时也要注意物理条件的选择及某些物理处理对真菌生长的影响. 从本文的 结果来看,只要从营养因子、物理条件及各种生态因子综合探讨 VAM 真菌生长的条件, 攻克 这类真菌的纯培养还是有希望的. 一旦它们的纯培养获得成功, 它们在生产上的应用就会取 得实质性的进展。

致谢：本文在表维蕃教授的悉心指导下进行,特此致谢。

\section{考文献}

[1] Gerdemann, J. W. \& Nicolson, T. H., Trans. Br. Mycol. Soc., 46(1963), 235.

[2] Fang, Y. C. et al., New Phyzol., 93(1983), 107.

[3] Mosse, B., J. G. Microbiol., 27(1962), 509.

[4] Koske, R. E., Mycologia, 73(1981), 288.

[5] Daniels, B. A. \& Graham,S. O., Mycologia, 68(1976), 108.

[6] Hepper, C. M. \& Smith, G. A., Trans. Br. Mycol. Soc., 66(1976), 189.

[7] Daniels, B. A. \& Trappe, J. M., Mycologia, 92(1980), 457.

[8] Mugnier, J. \& Mosse, B., Trans. Br. Mycol. Soc., 88(1987), 411.

[9] Mayo, K. et 1., Mycologia, 78(1986), 426. 